\title{
Identification of microplastics in surface water and Australian freshwater shrimp Paratya australiensis in Victoria, Australia ${ }^{\text {t3 }}$
}

\author{
Bingxu Nan ${ }^{a,}$, Lei Su ${ }^{\text {a, c }}$, Claudette Kellar ${ }^{b}$, Nicholas J. Craig a , Michael J. Keough a, \\ Vincent Pettigrove ${ }^{\mathrm{b}}$ \\ ${ }^{a}$ Centre for Aquatic Pollution Identification and Management (CAPIM), School of Biosciences, The University of Melbourne, Victoria, 3010, Australia \\ ${ }^{\mathrm{b}}$ Aquatic Environmental Stress Research Group (AQUEST), School of Science, RMIT University, PO Box 71, Bundoora, 3078, Victoria, Australia \\ c State Key Laboratory of Estuarine and Coastal Research, East China Normal University, Shanghai, 200062, China
}

\section{A R T I C L E I N F O}

\section{Article history:}

Received 7 August 2019

Received in revised form

20 December 2019

Accepted 20 December 2019

Available online 23 December 2019

\section{Keywords:}

Microplastics

Freshwater

Shrimp

Biomonitoring

Fibre

\begin{abstract}
A B S T R A C T
Compared to marine microplastics research, few studies have bio-monitored microplastics in inland waters. It is also important to understand the microplastics' uptake and their potential risks to freshwater species. The Australian glass shrimp Paratya australiensis (Family: Atyidae) is commonly found in fresh waterbodies in eastern Australia, and are sensitive to anthropogenic stressors but have a wide tolerance range to the natural environmental conditions. This study aimed to understand the microplastics' occurrence and types in water samples and the shrimp P. australiensis, and identify if the shrimp could be a suitable bioindicator for microplastic pollution. Surface water and $P$. australiensis across ten urban and rural freshwater sites in Victoria were sampled. In total, 30 water samples and 100 shrimp were analysed for microplastic content, and shrimp body weights and sizes were also recorded. Microplastics were picked, photographed and identified using FT-IR microscopy: in water samples, 57.9\% of items including suspect items were selected to identify; all microplastics found in shrimp samples were identified. Microplastics were present in the surface waters of all sites, with an average abundance of $0.40 \pm 0.27$ items/L. A total of $36 \%$ of shrimp contained microplastics with an average of $0.52 \pm 0.55$ items/ind $(24 \pm 31$ items/g). Fibre was the most common shape, and blue was the most frequent colour in both water and shrimp samples. The dominant plastic types were polyester in water samples, and rayon in shrimp samples. Even though results from this study show a relatively low concentration of microplastics in water samples in comparison with global studies, it is worth noticing that microplastics were regularly detected in fresh waterbodies in Victoria, Australia. Compared with water samples, shrimp contained a wider variety of plastic types, suggesting they may potentially behave as passive samplers of microplastics pollution in freshwater environments.
\end{abstract}

(c) 2019 Elsevier Ltd. All rights reserved.

\section{Introduction}

Microplastics (microscopic plastic, $0.1 \mu \mathrm{m}-5 \mathrm{~mm}$ in size) are a widespread anthropogenic pollutant (Phuong et al., 2016). They globally occur in terrestrial, freshwater and marine ecosystems (Cozar et al., 2014; Phuong et al., 2016; Prata, 2018; Reisser et al., 2013) and have become a major pollutant in the environment (Browne et al., 2011). Microplastics are found in many personal care products, such as face cleaning soaps, and are also generated from

\footnotetext{
This paper has been recommended for acceptance by Eddy Y. Zeng.

* Corresponding author.

E-mail address: bing.nan@unimelb.edu.au (B. Nan).
}

synthetic fibres in clothing and plastic beads used for industrial sandblasting (Chua et al., 2014). They are also created from the fragmentation of macroplastics by UV light, water turbulence or other physical or chemical degradation processes (Suhrhoff and Scholz-Bottcher, 2016). Urban areas, particularly industrial areas, and treated and untreated waste water are major sources of microplastic pollution in inland waters (Nizzetto et al., 2016; Windsor et al., 2019). Over 90\% of microplastics are removed from raw sewage by wastewater treatment plants and are retained in the sludge/biosolids (Carr et al., 2016). About 110-180 t of sludge is annually used as a fertiliser in agriculture in many regions (Nizzetto et al., 2016), so the microplastics in sludge could be another source of contamination to surface waters.

Several different sampling methods have been used for measuring 
microplastics in environmental samples, which makes comparisons between studies difficult (Prata et al., 2019). As environmental samples mainly reflect pollution across one time point, measuring microplastics in animals may provide more information given that microplatics may be retained in their body for a longer period of time (Qu et al., 2018). Many microplastics have been reported to be ingested by marine animals such as zooplankton, crustaceans, fish, seabirds and mammals (Abbasi et al., 2018; Avio et al., 2017; Devriese et al., 2015; Moore et al., 2001; Murray and Cowie, 2011; Van Cauwenberghe and Janssen, 2014). Several studies have shown that marine crustaceans are potentially ideal for assessing the occurrence of microplastics due to their filter, suspension, and/or depositfeeding strategies (Abbasi et al., 2018; Dawson et al., 2018). Compared with studies on marine species, there have been few freshwater species used to assess microplastic pollution. Studies surveying freshwater animals have mainly focused on higher trophic levels such as freshwater fish (Sanchez et al., 2014; Su et al., 2019), with fewer studies on macroinvertebrates (Nel et al., 2018; Su et al., 2018; Windsor et al., 2019). Each test species has its own bias depending on microplastic ingestion methods, behavioural responses to different types of microplastics, sizes and quantities of microplastics and habitat preferences, so different bioindicators may provide different information about microplastic pollution (Wesch et al., 2016). So it is important to choose a species with a wide distribution and tolerance for environmental factors that are capable of ingesting relatively large sizes of microplastics and can be compared across temporal and spatial scales (Su et al., 2018).

The Australian glass shrimp Paratya australiensis (Family: Atyidae) are common inhabitants of creeks, rivers and estuaries in Australia, from south-eastern South Australia to southern Queensland, and isolated populations also exist in northern Queensland (Cook et al., 2006; Walsh, 1993). They also frequently inhabit lentic waterbodies (Walsh, 1993) and can tolerate a broad range of salinities from fresh to marine waters (Kefford et al., 2004). As P. australiensis is commonly present in a variety of freshwater habitats, including moderately polluted waterbodies (Chessman, 2003), they can be used to assess microplastic pollution in degraded waters. Therefore, $P$. australiensis is likely to be an ideal candidate species for biomonitoring microplastic pollution.

Paratya australiensis has been used in ecotoxicology exposure experiments with heavy metals (Oulton et al., 2014; Vera et al., 2014), herbicides (atrazine and molinate) (Phyu et al., 2005) and pesticides (carbaryl, chlorpyrifos, cypermethrin, dimethoate, diuron and fenarimol) (Kumar et al., 2010). This paper is the first study that has assessed the occurrence of microplastics in P. australiensis or any other kind of Australian native freshwater species. It is the first study of its kind on freshwater crustaceans, globally.

This paper compares microplastic occurrence between freshwater water samples and shrimp inhabiting these freshwaters using a native Australian species, and evaluates the potential of using P. australiensis as a biomonitor of microplastic pollution. In particular, we: 1) sampled sites with no continuous point sources of pollution in Victoria, Australia, to make sure animal cohorts were not affected by high concentrations of point-source pollutants, and investigated the abundances and types of microplastics in water and shrimp respectively; 2) compared the characteristics of microplastics between water and shrimp samples; and 3) analysed the factors (shrimp size, weight and microplastic types) that may influence the microplastic uptake in shrimp.

\section{Materials and methods}

\subsection{Research area and sample collections}

Ten sites including streams and wetlands were surveyed from the Greater Melbourne Area (GMA) and from the Goulburn River catchment in northern central Victoria (Fig. 1; Supplementary materials Table S1). The Goulburn River catchment is a highly modified area for agriculture with a basin size of about $23,584 \mathrm{~km}^{2}$ (Shelton et al., 2001). The GMA is home to nearly 4.9 million people with a catchment area of approximately $12,800 \mathrm{~km}^{2}$ (Sharley et al., 2016). Sites A - E are located on the Goulburn River, and its tributaries: Sites A - C are along the Goulburn River and located north of the Great Dividing Range; Sites D and E are tributaries of the Goulburn River. Sites F-H, J and K are located in the Melbourne metropolitan area around the main city. These sites represented different cohort or populations of $P$. australiensis. Water and shrimp samples were collected once from each site during April to July 2018. All containers were rinsed using filtered deionised water before use, with water containers rinsed with in situ water at each site. Grab surface water samples (depth $0-5 \mathrm{~cm}$ ) were collected using three $5 \mathrm{~L}$ food-grade blue polypropylene jars at each site around shrimp habitats, water samples were gently collected to avoid the possible disturbance by re-suspended sediments. Paratya australiensis were collected around macrophytes (edge habitats) in waterbodies using macroinvertebrate dip nets. Whole shrimp samples were sacrificed and placed in a $250 \mathrm{~mL}$ glass jar with $100 \mathrm{~mL}$ 70\% filtered ethanol solution directly after sampling at each site and stored at $4{ }^{\circ} \mathrm{C}$ until processing.

\subsection{Isolation of microplastics}

All equipment used for processing samples was rinsed by filtered deionised water before use. Each water sample was filtered within $48 \mathrm{~h}$ after collection. Accurate volumes of three replicates of $5 \mathrm{~L}$ water samples were measured using glass cylinders first, and filtered through nylon membranes (Millipore NY2004700, pore size $=20 \mu \mathrm{m}$ ) using a vacuum pump in a fume hood separately. Each membrane was quickly transferred into a clean Petri dish for further examination.

Shrimp samples were processed within a week after collection. Due to variation in shrimp abundances across sites, a total of 8-12 shrimp were randomly picked at each site and body length and weight were recorded (Supplementary materials Table S2). The shrimp were then rinsed with filtered deionised water to dislodge any possible microplastics on their exoskeletons. The whole bodies were placed individually into small glass vials with foil lids. Alkaline hydrolysis was an important chemical for hydrolysing protein compounds in recent studies, and sodium hydroxide $(\mathrm{NaOH})$ was verified as a good tool for undertaking soft animal tissue dissolving experiments (Su et al., 2019). Shrimp samples were dissolved using $10 \mathrm{~mL} 2 \mathrm{~N} \mathrm{NaOH}$ at $60^{\circ} \mathrm{C}$ for $12 \mathrm{~h}$ in a water bath, which dissolved all of the tissue within the exoskeleton. The exoskeleton could then be picked out and examined, minimising errors in visual identification. Once the tissue dissolved, the sample solutions were filtered through $0.45 \mu \mathrm{m}$ nitrocellulose membranes (Millipore HAWP04700) using a vacuum pump in a fume hood. Each filtered membrane was then quickly placed in a clean Petri dish and covered with a lid for examination.

\subsection{Observation and validation of microplastics}

Microplastics on these filter membranes were observed using a Leica M125 Stereo microscope attached with a Leica MC 170 HD digital camera. Visual assessments were conducted to identify microplastics based on their physical identities and photos were taken to record their size, shape, colour and number. Microplastics were categorised into 4 shapes: fibre, film, fragment and pellet ( $\mathrm{Su}$ et al., 2018). Sizes of items were measured under Image J, fibres were measured using the freehand line tool from the start to end, 


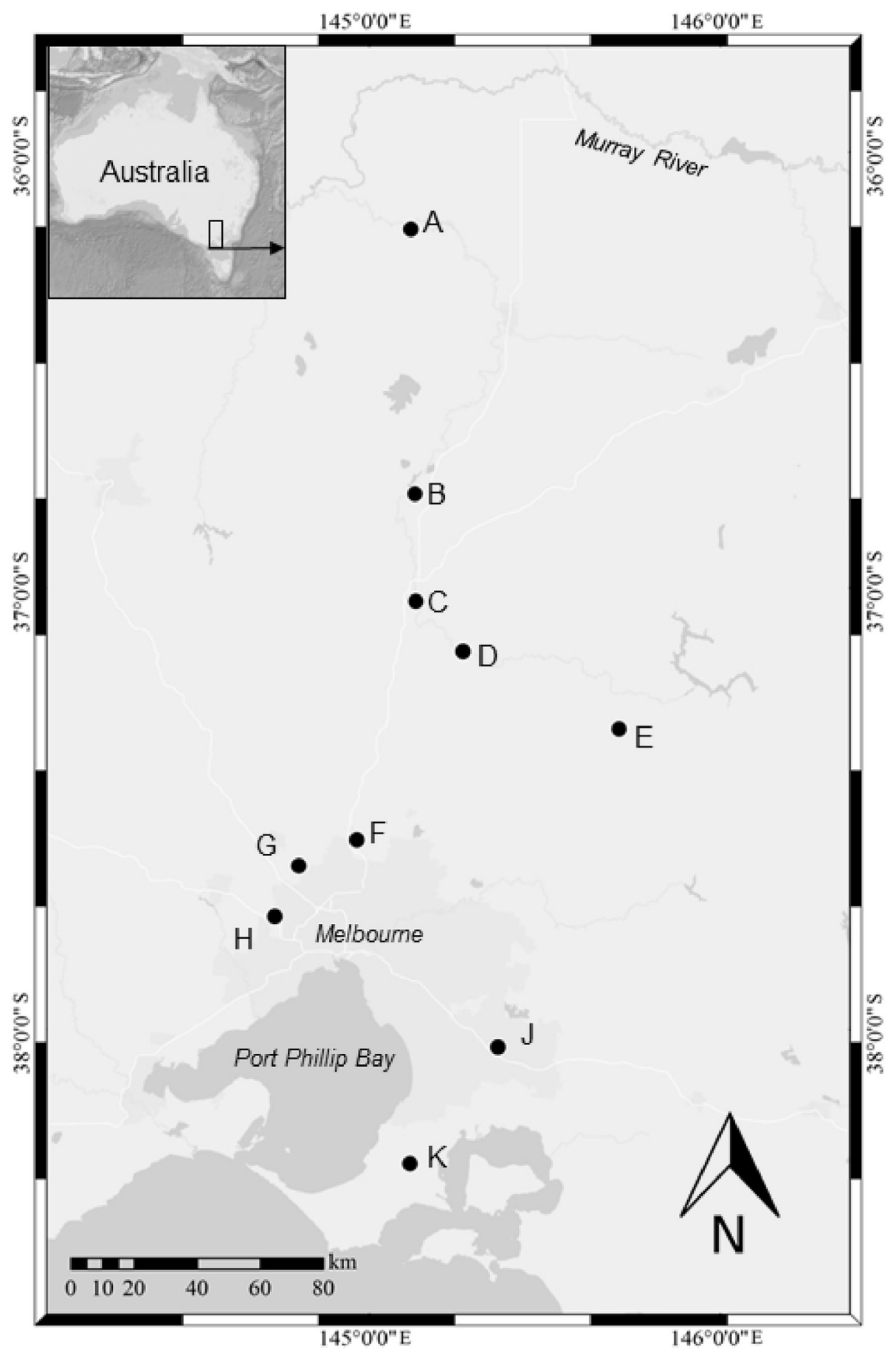

Fig. 1. Locations of sampling sites within Victoria, Australia.

and film, fragment and pellet were measured using the straightline tool to measure the maximum widths.

To ensure the accuracy of identifying microplastics ingested by shrimp and to understand the composition of microplastics, we conducted a 100\% FT-IR validation of the visually identified 199 items from shrimp samples. Sixty-two items including suspected ones after visual identifications were selected from the visually identified 107 items in water samples for validation, with a validation rate of $57.9 \%$, which is above the recommended level (50\%) (Hermsen et al., 2018). The specific polymer composition was determined under the attenuated total reflection (ATR) mode of a
micro-Fourier Transform Infrared Spectroscopy ( $\mu$-FT-IR, Bruker, LUMOS). All spectra were compared with a database from Bruker to verify. The spectra matching with a quality index more than $70 \%$ were accepted. The abundances of microplastics in shrimp and water were re-calculated by deducting the verified non-plastics.

\subsection{Quality control of the experiment}

Due to the ubiquitous presence of microplastics in the indoor environment, we undertook strict quality control to minimise the contamination of microplastics. The deionised water and $\mathrm{NaOH}$ 
solution applied in this study were all filtered using $20 \mu \mathrm{m}$ pore size membranes (Millipore NY2004700) in a fume hood before use. Wearing white cotton lab coats and clean nitrile examination gloves were mandatory during the experimental processes. Working surfaces were cleaned thoroughly before processing the samples. Before processing samples, 3 thoroughly cleaned Petri dishes were exposed in the fume hood for $30 \mathrm{~min}$ to check for background contamination, and no microplastics were found inside the Petri dishes.

We set up one blank control for every 2 shrimp samples and every 3 water samples, with a total of 50 blanks for shrimp and 10 blanks for water. For each blank, shrimp bodies were replaced by $2 \mathrm{~mL}$ filtered deionised water; blanks for water were conducted in 5 L filtered deionised water. Each blank were performed simultaneously with samples processing procedures. Nine items were found in blanks for shrimp samples, which equated to 0.18 items/ ind., 0.09 items $/ g$ and a detection rate of $12 \%$. Eight items were found in blanks for water samples and equated to 0.16 items/L. The results of this study were subtracted the mean level of background contamination data from those blanks.

There are two possible ways contamination of microplastics can occur during the sample processing procedures. Firstly, contamination may have occurred during the filtering of water samples with the nylon membrane. While this is a commonly used method for filtering environment samples quickly and avoids the possible contamination from the surrounding air (Li et al., 2018; Su et al., 2019), fibres from the nylon filter may have introduced some fibres. These fibres are however very different to the sampled items. To minimise contamination of nylon, all of the membranes were rinsed using the filtered deionised water before use and observation verification for microplastics before undergoing FT-IR analysis was conducted. Secondly, contamination may have come from the blue portable jars. To minimise the risk each jar was filled with filtered deionised water for $48 \mathrm{~h}$ before sampling. They were all checked visually and no microplastic pieces were found in any of the jars.

$70 \%$ ethanol was used to preserve the shrimp samples, which is a common preservative for invertebrate samples (Devriese et al., 2015; Windsor et al., 2019). It has been reported that some polymers like polyurethane and polycarbonate are incompatible with ethanol (Chambers et al., 2006). These polymers are generally not reported in samples from previous field surveys, so it is not considered to be an issue in the current study.

\subsection{Data analysis}

Microsoft Excel 2016 and SPSS 20.0 were used for data analysis. Since the data from this study were not normally distributed, Kruskal-Wallis Test was used to test for significant differences among different groups of data. A significance level of 0.05 was chosen. Map data was generated using Arc GIS 10.2. Microsoft Excel 2016 and Prism 9 were used for exporting data graphs.

\section{Results}

\subsection{Polymer identification in shrimp and water samples}

A total of 72 out of 199 items (36.2\%) in shrimp were confirmed as plastic using micro-Fourier Transform Infrared Spectroscopy. Of those verified microplastics, 11 polymer types were identified (Supplementary materials Table S3). The most commonly observed in shrimp was rayon (22.6\%) which was present at all 10 sites. Polyester was the second most abundant item (7.5\%) and was present at 9 sites. The remaining 9 types of plastics were comparatively uncommon and occurred at only 1 or 2 sites (Fig. 2; Supplementary materials Fig. S1).

A total of 107 items were observed within the water samples. Of these, 62 items from 9 sites were selected for FT-IR analyses in water samples, and 39 items were verified as plastics (62.9\%), comprising of 9 polymer types (Supplementary materials Table S4). Polyester (30.6\%) was the dominant polymer appearing in 7 sites, followed by polyamide (12.9\%) in 4 sites and rayon ( $8.1 \%$ ) in 3 sites (Fig. 2). The other 6 polymer types were collected from 1 to 2 sites respectively (Fig. 2; Supplementary materials Fig. S1).

\subsection{Abundances of microplastics in shrimp and water samples}

Overall, 36\% of shrimp across all sites contained microplastics, however there was large variation encountered between the number of microplastics observed within individuals at a particular site (Table 1). The average abundance (and the standard deviation) of microplastics in shrimp bodies was $0.52 \pm 0.55$ items/ind, or $2.4 \pm 3.1 \mathrm{items} / \mathrm{g}$. In water samples, $45 \mathrm{items}$ of microplastics were identified by their physical identities, and another 39 were verified by FT-IR results, so a total of 84 microplastics were detected from water samples. The average abundance (and the standard deviation) of microplastics in water samples was $0.40 \pm 0.27$ items/L

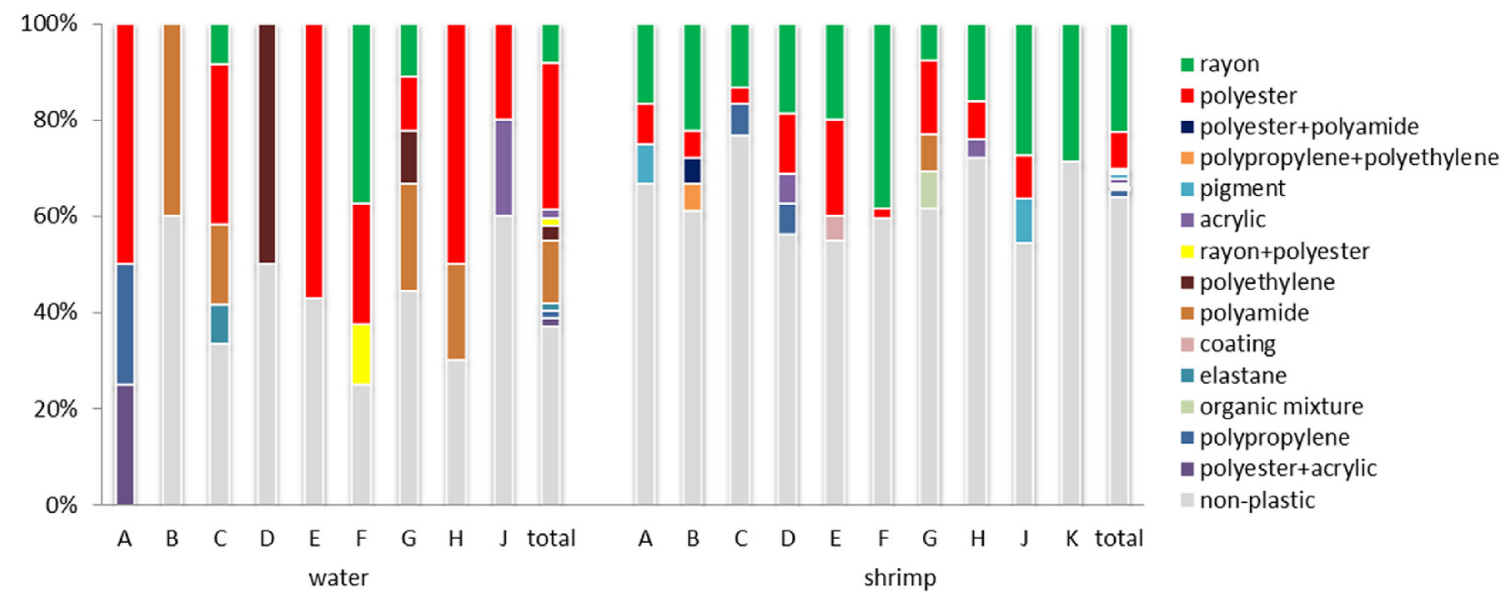

Fig. 2. Percentage of polymers identified within different sampling sites in Victoria, Australia. 
Table 1

Abundances of microplastics in shrimp Paratya Australiensis and water samples from each site*.

\begin{tabular}{llllll}
\hline \multirow{2}{*}{ site } & shrimp & & & water \\
\cline { 2 - 3 } & items/ind & items/g ww & \%detection & & items/L \\
\hline A & $0.32 \pm 0.76$ & $18 \pm 45$ & 26 & 21 & $0.11 \pm 0.11$ \\
B & $0.40 \pm 0.90$ & $3.8 \pm 6.3$ & 38 & & $0.43 \pm 0.19$ \\
C & $0.40 \pm 0.67$ & $8.2 \pm 13$ & 51 & $0.56 \pm 0.21$ \\
D & $0.70 \pm 0.83$ & $83 \pm 95$ & 46 & $0.25 \pm 0.42$ \\
E & $0.57 \pm 0.75$ & $5.2 \pm 5.8$ & 46 & $0.65 \pm 0.42$ \\
F & $1.4 \pm 2.1$ & $8.5 \pm 11$ & 38 & $0.24 \pm 0.20$ \\
G & $0.45 \pm 0.74$ & $3.5 \pm 4.4$ & 30 & $0.72 \pm 0.29$ \\
H & $0.40 \pm 0.79$ & $4.0 \pm 5.9$ & 51 & $0.43 \pm 0.52$ \\
J & $0.45 \pm 0.52$ & $5.7 \pm 6.0$ & 13 & $0.45 \pm 0.01$ \\
K & $0.070 \pm 0.46$ & $0.78 \pm 1.6$ & 36 & $0.17 \pm 0.31$ \\
Total & $0.52 \pm 0.55$ & $24 \pm 31$ & - & $0.40 \pm 0.27$ \\
$p^{* *}$ & 0.766 & 0.357 & & 0.207 \\
\hline
\end{tabular}

*Water samples from all sites contained microplastics, with a detection rate of $100 \%$ in each site. Abundances data are the average abundances and standard deviations. ** P-value was acquired from the Kruskal-Wallis Test, indicating the significant difference of microplastics abundance in water and shrimp among sampling sites.

across all sites. Water samples from each site contained microplastics, and less variation within sites was observed. There were no significant differences found in the variation of microplastic abundance in shrimp and water across different sites (Table 1). Blue was the dominant microplastic colour for both water (45\%) and shrimp samples (90\%) (Table 2).

\subsection{Characteristics of microplastics in water and shrimp samples}

Based on all water and shrimp samples, fibre was the most common polymer type that was present in all samples and comprised $58.3 \%-100.0 \%$ of the total polymers observed at each site (Fig. 3A and B). Almost all plastics observed in shrimp were fibres, with only 1 fragment found in the 100 shrimp sampled (Fig. 3B; Supplementary materials Fig. S2). Films and pellets were only found in water samples ( $\mathrm{n}=4$ and 1 respectively). Microplastic diameters ranged from 0.036 to $4.668 \mathrm{~mm}$ in water (mean $=0.942 \pm 0.835 \mathrm{~mm}$ ) and $0.190-4.214 \mathrm{~mm}$ in shrimp (mean $=0.764 \pm 0.575 \mathrm{~mm}$ ) (Fig. 3C and D). Overall, $66.7 \%$ of plastics in water and $75.0 \%$ in shrimp were less than $1 \mathrm{~mm}$ in size (Fig. 4). Microplastics found in the water were larger on average than those found in shrimp (Fig. 4); however, this difference was not statistically significant $(P>0.05)$.

\subsection{Microplastics uptake depends on size and weight of shrimp}

For shrimp samples, we calculated microplastic abundance in each individual and tested significant differences in different groups. There were no significant correlations found between the

Table 2

Colour distributions of microplastics from water and shrimp samples.

\begin{tabular}{llllll}
\hline \multirow{2}{*}{ Colour } & \multicolumn{2}{l}{ Number of items } & & \multicolumn{2}{c}{ Percentage of items (\%) } \\
\cline { 2 - 3 } & Water & Shrimp & & Water & Shrimp \\
\hline Black & 7 & - & & 8.3 & - \\
Blue & 38 & 65 & & 45 & 90 \\
Green & 1 & 1 & & 1.2 & 1.4 \\
Red & 6 & 3 & & 7.1 & 4.2 \\
Transparent & 18 & 2 & & 21 & 2.8 \\
White & 6 & - & & 7.1 & - \\
Yellow & 8 & - & & 9.5 & - \\
Gray & - & 1 & & - & 1.4 \\
Total & 84 & 72 & & & \\
\hline
\end{tabular}

size/total weight, of shrimp and the abundance of microplastics found in their bodies ( $p>0.05$ ) (Fig. $5 \mathrm{~A}$ and $\mathrm{C}$ ). The lengths/ weights of shrimp in both detect and absent groups were largely in the same range, there was no significant positive correlation in each group of data ( $\mathrm{p}>0.05)$ (Fig. $5 \mathrm{~B}$ and $\mathrm{D}$ ).

\section{Discussion}

This study has provided an initial knowledge of microplastic pollution in Australian native freshwater species, and provided a new pathway for undergoing microplastics biomonitoring experiments in the field using healthy animals. In general, a variety of invertebrate animals have been identified as being potentially good bioindicators of microplastic pollution in their respective habitats based on their life-history strategies (Abbasi et al., 2018; Avio et al., 2017; Ory et al., 2017; Sanchez et al., 2014). Compared to microplastic pollution studies with marine organisms, there is still a lack of knowledge in freshwater organisms. This is the first time that a freshwater crustacean has been used as a bioindicator to assess microplastic pollution. Paratya australiensis in freshwater environments are one of the most common crustaceans in Australia and may be an ideal bioindicator to biomonitor microplastic pollution.

\subsection{The level and trend of microplastic pollution in Victoria, Australia}

Summary results of other studies investigating microplastic pollution in freshwater around the world are presented in Table 3. Even though the sampling sites, method and seasons were quite different in these studies, there are relatively lower concentrations of microplastics in this study compared to many other studies globally. Our study suggested that Victorian waterways in Australia had higher microplastic concentrations than those reported from Europe and Japan, but lower concentrations than those reported in China and the USA. However, some of the studies cited collected water samples from polluted waterbodies that regularly receive treated wastewaters and/or industrial runoff. For our study, we focused on surveying waterbodies where there was no direct source of microplastic pollution within close proximity; the results suggest that the microplastics pollution in Australia is largely ubiquitous within rural and urban areas.

In this study, there were no significant differences in water or shrimp samples across different sites. Based on data from Table .1, in Goulburn River catchment the microplastic abundance in waterbodies was generally higher in a headwater site $\mathrm{E}$ compared with sites in the mainstream (A to C). But it was hard to compare the concentrations between shrimp and water samples within one site, as the concentrations may be significantly different like site D and F. As an irregular creek, Site D may experience some pollution events from upstream. Site $\mathrm{F}$ is a creek located in the north of the GMA, this creek was intermittently polluted by farmlands and dwellings' wastes. When the polluting events happened in these sites, microplastics in the water may flush downstream or accumulate in the sediment in a short period of time, while the microplastics captured by animals may have persisted for a longer time. Based on experiments in our lab, this species usually keep their gut contents for $12-24 \mathrm{~h}$, with some individuals still containing microplastics after $48 \mathrm{~h}$. Similar results were also found in other crustacean species (Chua et al., 2014; Dawson et al., 2018; Gray and Weinstein, 2017). These results indicate that using organisms to survey microplastics can provide longer-term data of the microplastics polluting events, and using shrimp as a biomonitoring tool is effective and convenient due to their broader daily swimming areas and faster water filtering speeds (Dawson et al., 2018). They may also capture relatively smaller 
A

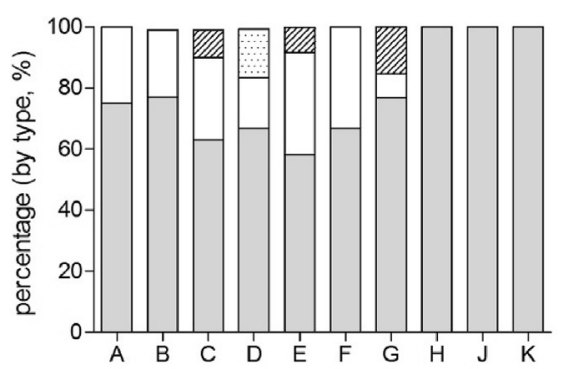

C

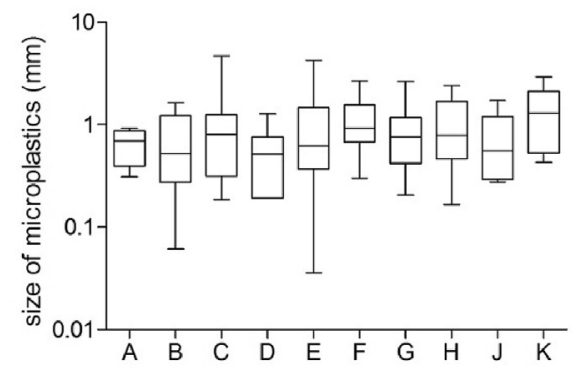

B

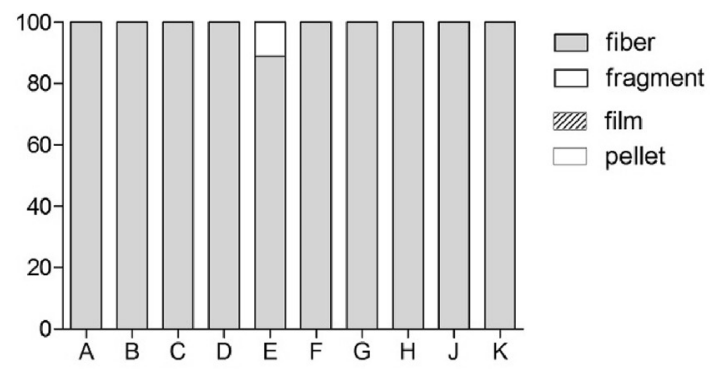

D

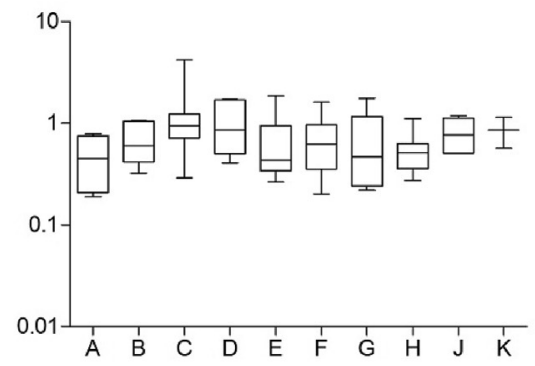

Fig. 3. Type and size distribution of microplastics from water (A and C) and shrimp (B and D) samples in 10 different sites.
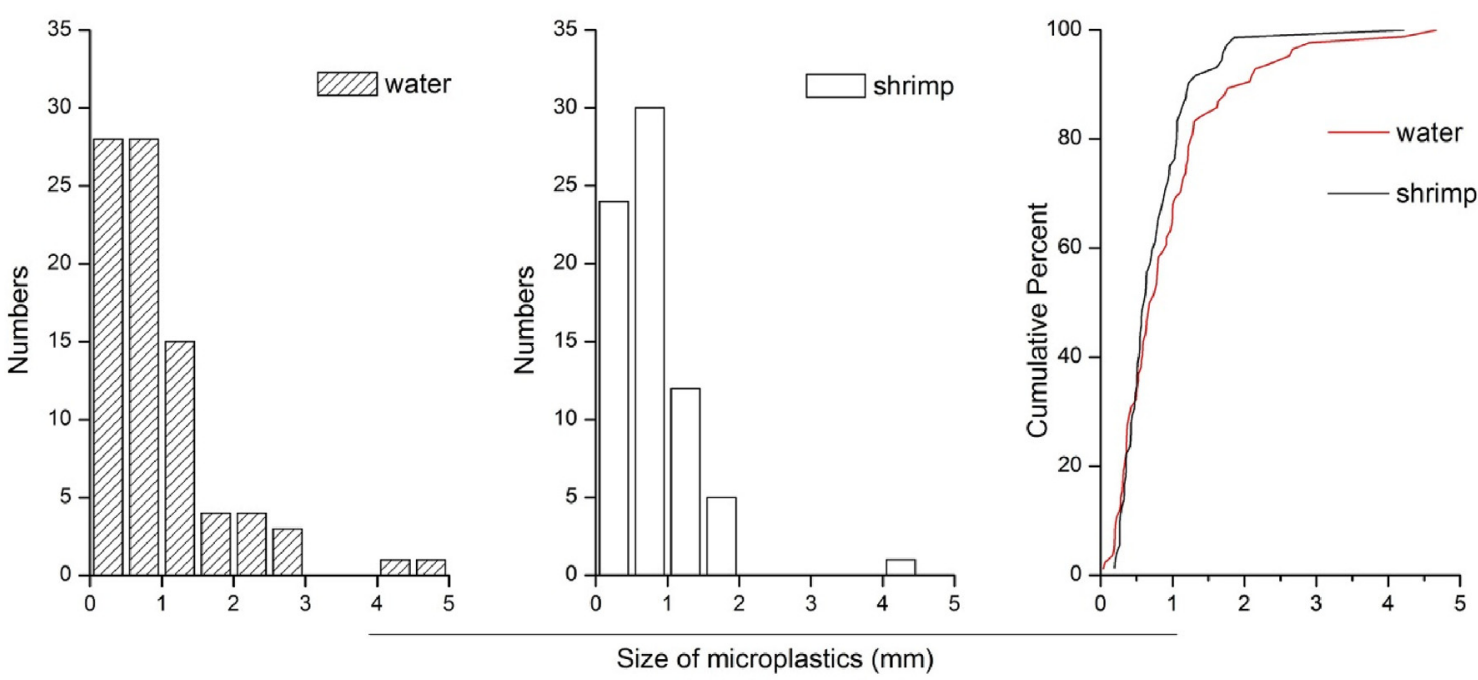

Fig. 4. Size distribution of microplastics in water and shrimp.

microplastics in the environment, and make microplastics easier to find and detect. Site $\mathrm{K}$ is a protected drinking water supply catchment for a part of GMA resident, yet even within this area, some microplastics were still present.

\subsection{Biomonitoring microplastics using freshwater species}

Prior to this study there have only been three studies that have assessed microplastics in freshwater macroinvertebrates. Windsor et al. (2019) surveyed macroinvertebrates in the vicinity of treated wastewater treatment plant discharges in South Wales valleys, United Kingdom, and observed a mean microplastic detection rate of approximately 50\%. Nel et al. (2018) examined chironomids from a series of polluted sites along the Bloukrans River, South Africa, and reported a mean detection rate of $86.5 \%$ and
0.37-1.12 items/mg ww. Su et al. (2018) surveyed Asian clam (Corbicula fluminea) from the Yangtze River Delta, China, and the average detection rate and abundance was $96 \%$ and 2.5 items/ind.

Even though Paratya australiensis is relatively smaller than other freshwater species (such as fish) used in biomonitoring microplastics, it has been shown to be a useful tool for biomonitoring microplastics based on our results. We conducted FTIR verifications for all picked items in shrimp and treated failed verified items as non-plastic to make sure all of the results presented were plastics. By using this method in this study, the detection rate was still $36 \%$, with an average abundance of 0.52 items/ind ( 23.73 items/g ww). Given different studies have targeted species of different sizes and biomasses, it is hard to compare the data directly, but it can be largely concluded that the detection rate of microplastics was in relatively low prevalence in these sites compared to similar studies, 
A

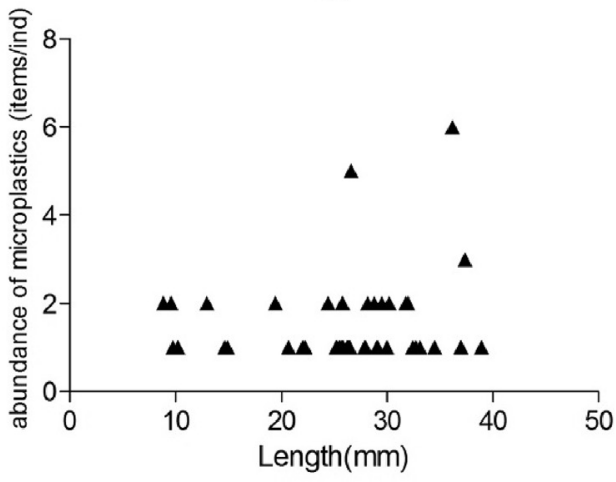

C

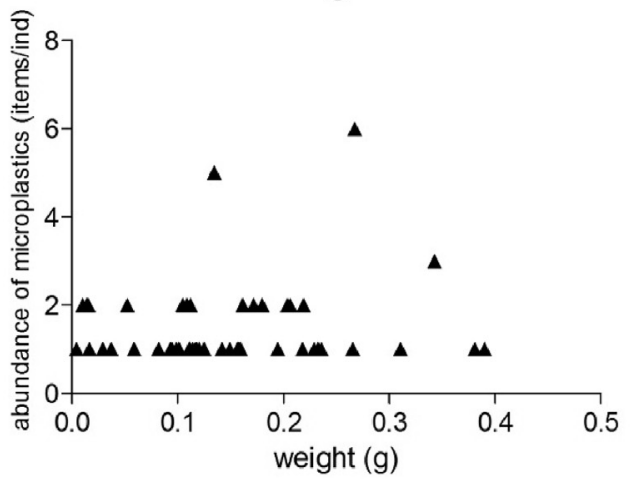

B

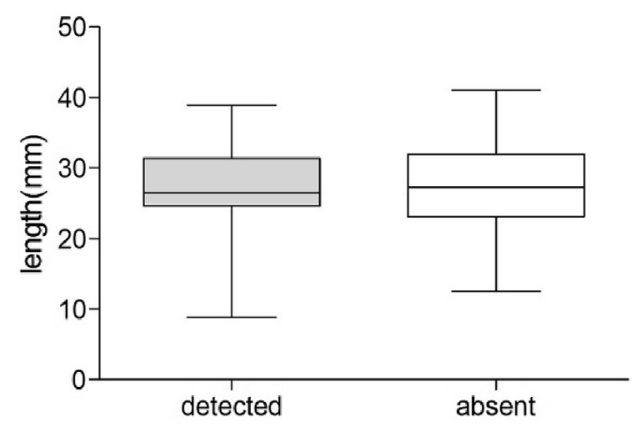

D

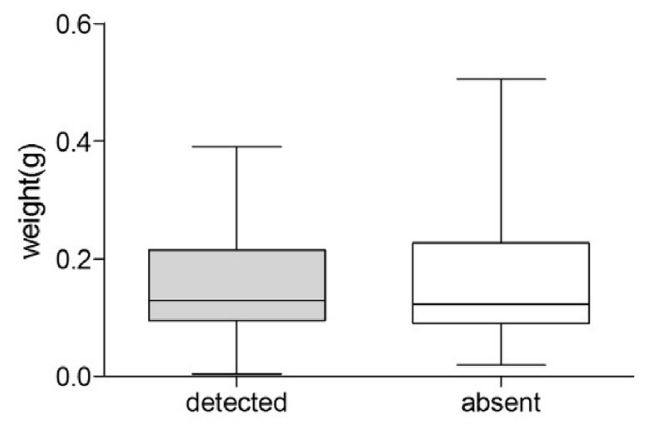

Fig. 5. Microplastic abundance in relation to length and weight of shrimp (A and C), and Size and weight distribution of shrimp (B and D) with and without microplastics.

Table 3

Studies on microplastic pollution in freshwater samples around the world.

\begin{tabular}{|c|c|c|c|}
\hline Location & Abundance $^{\mathrm{a}}($ items/L) & Primary polymer & Reference \\
\hline Freshwater waterbodies in Victoria, Australia & 0.4 & PE, PA & This study \\
\hline Yangtze River Estuary, China & 4.1373 & $\mathrm{~N} / \mathrm{A}$ & Zhao et al. (2014) \\
\hline Three Gorges Reservoir, China & 4.703 & PS, PP, PE & Di and Wang (2018) \\
\hline Urban waters of Wuhan, China & Lake: 1.66-8.925, River: 2.5167-2.933 & PETE, PP & Wang et al. (2017) \\
\hline Middle-Lower Yangtze River Basin, China & $0.5-3.1$ & Cellophane, PETE, PET & Su et al. (2018) \\
\hline Carpathian basin, Europe & $0.004-0.032$ & PP, PE & Bordos et al. (2019) \\
\hline Rivers in Japan & 0.0016 & $\mathrm{~N} / \mathrm{A}$ & Kataoka et al. (2019) \\
\hline Pearl River estuary, China & urban section: 19.86 , estuary: 8.902 & PA, Cellophane & Yan et al. (2019) \\
\hline Snake and Lower Columbia Rivers, USA & 0.91 & $\mathrm{~N} / \mathrm{A}$ & Kapp and Yeatman (2018) \\
\hline Gallatin watershed, USA & 1.2 & Rayon, PET & Barrows et al. (2018) \\
\hline Antua River, Portugal & $0.058-1.265$ & PE, PP & Rodrigues et al. (2018) \\
\hline Lake Chiusi, Italy & $0.00048-0.000282$ & $\mathrm{~N} / \mathrm{A}$ & Fischer et al. (2016) \\
\hline Lake Bolsena, Italy & $0.00021-0.000408$ & $\mathrm{~N} / \mathrm{A}$ & Fischer et al. (2016) \\
\hline
\end{tabular}

${ }^{a}$ Mean values or data ranges from surveys.

but the average concentrations in shrimp bodies was much higher than the result from Nel et al. (2018). Thus, Paratya australiensis has greater potential in biomonitoring microplastics, even though the sampling sizes needed may be greater than other macroinvertebrates.

\subsection{Characteristics of microplastics in water and shrimp samples}

Results (Fig. 3B; Supplementary materials Fig. S2) showed that shrimp mainly ingested microfibers, but not the other 3 types (films, pellets and fragments); while all 4 types were found in water samples, even though fibres were still the dominant type (Fig. 3A). Larger plastic pieces are unable to break down into smaller parts in a short period of time in the environment (Weinstein et al., 2016), and are unlikely to be ingested by macroinvertebrates due to their larger sizes, so we may not be able to find a lot of pellets, films and fragments in macroinvertebrates. On the other hand, microfibres are relatively smaller and can directly be generated by daily human activities and had higher concentrations in the water than the other 3 types, so they may be easier to capture by macroinvertebrates in the water environment. Results from Asian clams also suggested microfibers were the most common type in organisms (Su et al., 2018).

There were no significant differences in the size of microplastics observed between water and shrimp. However, microplastic sizes uptakes by shrimp were generally smaller than those from water 
samples (Fig. 4), although the extra small plastics (e.g. nanoplastics) might be missing from our observations due to the limitations of the method. Due to the tiny size and ingestion behaviours of shrimp, they tend to ingest relatively smaller microplastics.

Microplastic uptake was unaffected by shrimp size and weight (Fig. 5B and D). Usually, large shrimp have heavier bodies, fully developed ingestion systems and are older than small shrimp (Walsh, 1993), but there were no large differences for the microplastic ingestion rates and behaviours between larger and smaller shrimp from our results. However, given that the number of shrimp and size ranges were limited in this study, the relationship between microplastic ingestion rates and sizes of shrimp should be investigated in the future.

Even though there were more types of microplastics ingested by shrimp based on results of polymer identifications, there were still certain types that only appeared in water samples (Fig. 2). Moreover, from the colour distribution results, almost all of the items we found in shrimp bodies were blue in colour, despite there being a wide assortment of other colours in the water samples. A 2017 study on microplastic ingestion in fish (Decapterus muroadsi) suggested that they could confuse blue microplastics with their similarly-coloured prey (Ory et al., 2017), but it is not known if shrimp may have evolved behavioural preferences on their ingestion of foodstuffs regarding colouration. Results also suggest that in order to comprehensively understand the occurrence of microplastics in a freshwater environment both surface water and an organism, such as a shrimp should be used.

\section{Conclusion}

This study surveyed the microplastic pollution extant within Australian fresh waterbodies using an indigenous shrimp species Paratya australiensis, as well as a more conventional bioindicator of microplastic pollution. The results suggest that microplastics were widely distributed across different areas in Victoria, Australia, although the concentrations were not high compared to other freshwater studies globally. By including the shrimp in our study, we found that they primarily ingest microplastics of a particular type and colour, and ingest a broad range of sizes of microfibers. This suggests they may be a promising tool for future biomonitoring of microplastic pollution within the environment. Also, future surveys of microplastics in the environment should consider including both point-source sampling and passive samplers to strengthen our understanding between the two.

\section{Notes}

The authors declare no competing financial interest.

\section{CRediT authorship contribution statement}

Bingxu Nan: Conceptualization, Methodology, Validation, Formal analysis, Investigation, Resources, Writing - original draft, Writing - review \& editing, Visualization, Funding acquisition. Lei Su: Methodology, Validation, Investigation. Claudette Kellar: Writing - review \& editing, Resources, Supervision. Nicholas J. Craig: Validation, Writing - review \& editing. Michael J. Keough: Formal analysis, Supervision. Vincent Pettigrove: Supervision, Writing - review \& editing.

\section{Acknowledgements}

We thank Daniel MacMahon for the assistance of sample collection works, and thank the Materials Characterisation and Fabrication Platform, the University of Melbourne for the technician assistance of polymer identification. This work was partially funded by The Holsworth Wildlife Research Endowment \& The Ecological Society of Australia.

\section{Appendix A. Supplementary data}

Supplementary data to this article can be found online at https://doi.org/10.1016/j.envpol.2019.113865.

\section{References}

Abbasi, S., Soltani, N., Keshavarzi, B., Moore, F., Turner, A., Hassanaghaei, M., 2018. Microplastics in different tissues of fish and prawn from the Musa Estuary, Persian Gulf. Chemosphere 205, 80-87.

Avio, C.G., Cardelli, L.R., Gorbi, S., Pellegrini, D., Regoli, F., 2017. Microplastics pollution after the removal of the Costa Concordia wreck: first evidences from a biomonitoring case study. Environ. Pollut. 227, 207-214.

Barrows, A.P.W., Christiansen, K.S., Bode, E.T., Hoellein, T.J., 2018. A watershed-scale, citizen science approach to quantifying microplastic concentration in a mixed land-use river. Water Res. 147, 382-392.

Bordos, G., Urbanyi, B., Micsinai, A., Kriszt, B., Palotai, Z., Szabo, I., Hantosi, Z. Szoboszlay, S., 2019. Identification of microplastics in fish ponds and natura freshwater environments of the Carpathian basin, Europe. Chemosphere 216, $110-116$.

Browne, M.A., Crump, P., Niven, S.J., Teuten, E., Tonkin, A., Galloway, T., Thompson, R., 2011. Accumulation of microplastic on shorelines woldwide: sources and sinks. Environ. Sci. Technol. 45, 9175-9179.

Carr, S.A., Liu, J., Tesoro, A.G., 2016. Transport and fate of microplastic particles in wastewater treatment plants. Water Res. 91, 174-182.

Chambers, S., Peddie, B., Pithie, A., 2006. Ethanol disinfection of plastic-adherent micro-organisms. J. Hosp. Infect. 63, 193-196.

Chessman, B.C., 2003. New sensitivity grades for Australian river macroinvertebrates. Mar. Freshw. Res. 54, 95-103.

Chua, E.M., Shimeta, J., Nugegoda, D., Morrison, P.D., Clarke, B.O., 2014. Assimilation of polybrominated diphenyl ethers from microplastics by the marine amphipod, Allorchestes compressa. Environ. Sci. Technol. 48, 8127-8134.

Cook, B.D., Baker, A.M., Page, T.J., Grant, S.C., Fawcett, J.H., Hurwood, D.A., Hughes, J.M., 2006. Biogeographic history of an Australian freshwater shrimp. Paratya australiensis (Atyidae): the role life history transition in phylogeographic diversification. Mol. Ecol. 15, 1083-1093.

Cozar, A., Echevarria, F., Gonzalez-Gordillo, J.I., Irigoien, X., Ubeda, B., HernandezLeon, S., Palma, A.T., Navarro, S., Garcia-de-Lomas, J., Ruiz, A., Fernandez-dePuelles, M.L., Duarte, C.M., 2014. Plastic debris in the open ocean. Proc. Natl. Acad. Sci. U. S. A. 111, 10239-10244.

Dawson, A.L., Kawaguchi, S., King, C.K., Townsend, K.A., King, R., Huston, W.M., Bengtson Nash, S.M., 2018. Turning microplastics into nanoplastics through digestive fragmentation by Antarctic krill. Nat. Commun. 9, 1001.

Devriese, L.I., van der Meulen, M.D., Maes, T., Bekaert, K., Paul-Pont, I., Frere, L. Robbens, J., Vethaak, A.D., 2015. Microplastic contamination in brown shrimp (Crangon crangon, Linnaeus 1758) from coastal waters of the southern north sea and channel area. Mar. Pollut. Bull. 98, 179-187.

Di, M., Wang, J., 2018. Microplastics in surface waters and sediments of the three Gorges reservoir, China. Sci. Total Environ. 616-617, 1620-1627.

Fischer, E.K., Paglialonga, L., Czech, E., Tamminga, M., 2016. Microplastic pollution in lakes and lake shoreline sediments - a case study on Lake Bolsena and Lake Chiusi (central Italy). Environ. Pollut. 213, 648-657.

Gray, A.D., Weinstein, J.E., 2017. Size-and shape-dependent effects of microplastic particles on adult daggerblade grass shrimp (Palaemonetes pugio). Environ. Toxicol. Chem. 36, 3074-3080.

Hermsen, E., Mintenig, S.M., Besseling, E., Koelmans, A.A., 2018. Quality criteria for the analysis of microplastic in biota samples: a critical review. Environ. Sci. Technol. 52, 10230-10240.

Kapp, K.J., Yeatman, E., 2018. Microplastic hotspots in the snake and lower Columbia rivers: a journey from the greater yellowstone ecosystem to the Pacific ocean. Environ. Pollut. 241, 1082-1090.

Kataoka, T., Nihei, Y., Kudou, K., Hinata, H., 2019. Assessment of the sources and inflow processes of microplastics in the river environments of Japan. Environ. Pollut. 244, 958-965.

Kefford, B.J., Papas, P.J., Metzeling, L., Nugegoda, D., 2004. Do laboratory salinity tolerances of freshwater animals correspond with their field salinity? Environ. Pollut. 129, 355-362.

Kumar, A., Correll, R., Grocke, S., Bajet, C., 2010. Toxicity of selected pesticides to freshwater shrimp, Paratya australiensis (Decapoda: Atyidae): use of time series acute toxicity data to predict chronic lethality. Ecotoxicol. Environ. Saf. 73, 360-369.

Li, H.X., Ma, L.S., Lin, L., Ni, Z.X., Xu, X.R., Shi, H.H., Yan, Y., Zheng, G.M., Rittschof, D. 2018. Microplastics in oysters saccostrea cucullata along the pearl river estuary, China. Environ. Pollut. 236, 619-625.

Moore, C.J., Moore, S.L., Leecaster, M.K., Weisberg, S.B., 2001. A comparison of plastic and plankton in the North Pacific central gyre. Mar. Pollut. Bull. 42, 1297-1300. Murray, F., Cowie, P.R., 2011. Plastic contamination in the decapod crustacean 
Nephrops norvegicus (Linnaeus, 1758). Mar. Pollut. Bull. 62, 1207-1217.

Nel, H.A., Dalu, T. Wasserman, R.J., 2018. Sinks and sources: assessing microplastic abundance in river sediment and deposit feeders in an Austral temperate urban river system. Sci. Total Environ. 612, 950-956.

Nizzetto, L., Futter, M., Langaas, S., 2016. Are agricultural soils dumps for microplastics of urban origin? Environ. Sci. Technol. 50, 10777-10779.

Ory, N.C., Sobral, P., Ferreira, J.L., Thiel, M., 2017. Amberstripe scad Decapterus muroadsi (Carangidae) fish ingest blue microplastics resembling their copepod prey along the coast of Rapa Nui (Easter Island) in the South Pacific subtropical gyre. Sci. Total Environ. 586, 430-437.

Oulton, L.J., Taylor, M.P., Hose, G.C., Brown, C., 2014. Sublethal toxicity of untreated and treated stormwater $\mathrm{Zn}$ concentrations on the foraging behaviour of Paratya australiensis (Decapoda: Atyidae). Ecotoxicology 23, 1022-1029.

Phuong, N.N., Zalouk-Vergnoux, A., Poirier, L., Kamari, A., Chatel, A., Mouneyrac, C., Lagarde, F., 2016. Is there any consistency between the microplastics found in the field and those used in laboratory experiments? Environ. Pollut. 211, $111-123$.

Phyu, Y.L., Warne, M.S., Lim, R.P., 2005. Toxicity and bioavailability of atrazine and molinate to the freshwater shrimp (Paratya australiensis) under laboratory and simulated field conditions. Ecotoxicol. Environ. Saf. 60, 113-122.

Prata, J.C., 2018. Airborne microplastics: consequences to human health? Environ. Pollut. 234, 115-126.

Prata, J.C., da Costa, J.P., Duarte, A.C., Rocha-Santos, T., 2019. Methods for sampling and detection of microplastics in water and sediment: a critical review. Trac. Trends Anal. Chem. 110, 150-159.

Qu, X., Su, L., Li, H., Liang, M., Shi, H., 2018. Assessing the relationship between the abundance and properties of microplastics in water and in mussels. Sci. Tota Environ. 621, 679-686.

Reisser, J., Shaw, J., Wilcox, C., Hardesty, B.D., Proietti, M., Thums, M., Pattiaratchi, C. 2013. Marine plastic pollution in waters around Australia: characteristics, concentrations, and pathways. PLoS One 8, e80466.

Rodrigues, M.O., Abrantes, N., Goncalves, F.J.M., Nogueira, H., Marques, J.C., Goncalves, A.M.M., 2018. Spatial and temporal distribution of microplastics in water and sediments of a freshwater system (Antua River, Portugal). Sci. Total Environ. 633, 1549-1559.

Sanchez, W., Bender, C., Porcher, J.M., 2014. Wild gudgeons (Gobio gobio) from French rivers are contaminated by microplastics: preliminary study and first evidence. Environ. Res. 128, 98-100.

Sharley, D.J., Sharp, S.M., Bourgues, S., Pettigrove, V.J., 2016. Detecting long-term temporal trends in sediment-bound trace metals from urbanised catchments. Environ. Pollut. 219, 705-713.
Shelton, D., Cork, S., Binning, C., Parry, R., Hairsine, P., Vertessy, R., Stauffacher, M., 2001. Application of an Ecosystem Services Inventory Approach to the Goulburn Broken Catchment, Third Australian Stream Management Conference. Cooperative Research Centre for Catchment Hydrology Brisbane, QLD, pp. 157-162.

Su, L., Cai, H., Kolandhasamy, P., Wu, C., Rochman, C.M., Shi, H., 2018. Using the Asian clam as an indicator of microplastic pollution in freshwater ecosystems. Environ. Pollut. 234, 347-355.

Su, L., Nan, B., Hassell, K.L., Craig, N.J., Pettigrove, V., 2019. Microplastics biomonitoring in Australian urban wetlands using a common noxious fish (Gambusia holbrooki). Chemosphere 228, 65-74.

Suhrhoff, T.J., Scholz-Bottcher, B.M., 2016. Qualitative impact of salinity, UV radiation and turbulence on leaching of organic plastic additives from four common plastics - a lab experiment. Mar. Pollut. Bull. 102, 84-94.

Van Cauwenberghe, L., Janssen, C.R., 2014. Microplastics in bivalves cultured for human consumption. Environ. Pollut. 193, 65-70.

Vera, C.L., Hyne, R.V., Patra, R., Ramasamy, S., Pablo, F., Julli, M., Kefford, B.J., 2014 Bicarbonate toxicity to Ceriodaphnia dubia and the freshwater shrimp Paratya australiensis and its influence on zinc toxicity. Environ. Toxicol. Chem. 33, 1179-1186.

Walsh, C.J., 1993. Larval development of Paratya australiensis Kemp, 1917 (Decapoda: Caridea: Atyidae), reared in the laboratory, with comparisons of fecundity and egg and larval size between estuarine and riverine environments. J. Crustacean. Biol. 13, 456-480.

Wang, W., Ndungu, A.W., Li, Z., Wang, J., 2017. Microplastics pollution in inland freshwaters of China: a case study in urban surface waters of Wuhan, China. Sci. Total Environ. 575, 1369-1374.

Weinstein, J.E., Crocker, B.K., Gray, A.D., 2016. From macroplastic to microplastic: degradation of high-density polyethylene, polypropylene, and polystyrene in a salt marsh habitat. Environ. Toxicol. Chem. 35, 1632-1640.

Wesch, C., Bredimus, K., Paulus, M., Klein, R., 2016. Towards the suitable monitoring of ingestion of microplastics by marine biota: a review. Environ. Pollut. 218, 1200-1208.

Windsor, F.M., Tilley, R.M., Tyler, C.R., Ormerod, S.J., 2019. Microplastic ingestion by riverine macroinvertebrates. Sci. Total Environ. 646, 68-74.

Yan, M., Nie, H., Xu, K., He, Y., Hu, Y., Huang, Y., Wang, J., 2019. Microplastic abundance, distribution and composition in the pearl river along Guangzhou city and pearl river estuary, China. Chemosphere 217, 879-886.

Zhao, S., Zhu, L., Wang, T., Li, D., 2014. Suspended microplastics in the surface water of the Yangtze Estuary System, China: first observations on occurrence, distribution. Mar. Pollut. Bull. 86, 562-568. 


\section{University Library}

\section{- M M N E R VA A gateway to Melbourne's research publications}

Minerva Access is the Institutional Repository of The University of Melbourne

Author/s:

Nan, B;Su, L;Kellar, C;Craig, NJ;Keough, MJ;Pettigrove, V

Title:

Identification of microplastics in surface water and Australian freshwater shrimp Paratya australiensis in Victoria, Australia

Date:

2020-04-01

Citation:

Nan, B., Su, L., Kellar, C., Craig, N. J., Keough, M. J. \& Pettigrove, V. (2020). Identification of microplastics in surface water and Australian freshwater shrimp Paratya australiensis in Victoria, Australia. ENVIRONMENTAL POLLUTION, 259, https://doi.org/10.1016/ j.envpol.2019.113865.

Persistent Link:

http://hdl.handle.net/11343/267318 